\title{
Research on Determination of Acrylamide in Fried Food by Flow Injection Chemiluminescence
}

\author{
Yun Li, Xiuli Zhang \\ Changchun Sci-Tech University, Jilin, Changchun, China, 130600
}

\begin{abstract}
In order to establish a novel flow injection chemiluminescence method for the analysis of trace acrylamide in fried foods, the acrylamide in the sample was extracted, and its effect on Luminol-Hydrogen Peroxide Chemical luminescence system to enhance the role of the determination of the conditions of the system to optimize and discuss the system. The results showed that the linear range of acrylamide was $1.0 \times 10-6 \sim 1.0 \times 10-3 \mathrm{~mol} / \mathrm{L}$, the correlation coefficient $r=0.9993$, the detection limit was $3.95 \times 10-8 \mathrm{~mol} / \mathrm{L}$, The relative standard deviation (RSD) of the sample was $1.3 \% \sim 107 \%$, and the relative standard deviation (RSD) was $1.3 \%(\mathrm{n}=9)$. The method is simple and quick, low cost, practical, for the determination of fried foods in the acrylamide, the results are satisfactory.
\end{abstract}

Keywords: Flow Injection Chemiluminescence; Fried Food; Acrylamide

\section{Introduction}

In daily life, often with fried foods such as french fries, high temperature toast and other staple food crowd, will intake a certain amount of acrylamide [1], which there are potential health risks. Therefore, the establishment of a sensitive and reliable, low cost, simple and practical determination of acrylamide in food rapid analysis method, to protect food safety, maintenance of human health has some practical significance.

At present, the determination of acrylamide in food is mainly by gas chromatography-mass spectrometry [2], gas chromatography, high performance liquid chromatography, high performance liquid chromatography-mass spectrometry, ion chromatography, ultraviolet-visible spectrophotometry. Most of these methods need to use a fixed large-scale precision instruments, costly, cumbersome operation, is not conducive to on-site rapid detection. Flow injection chemiluminescence has the advantages of high sensitivity, fast analysis speed, simple operation, low cost, portable instrument, and convenient field measurement. It has been widely used in the determination of food, medicine and biological samples [3]. In this study, based on the enhancement of lum inol-H 2 O 2 chemiluminescence system by acrylamide, a new analytical method of flow injection chemiluminescence of acrylamide was established, which was used for the determination of fried food.

\section{Materials and Methods}

Materials. Shrimp, rice crust, potato chips, etc. purchased in Zhengzhou City Dennis supermarket.

Instruments and Equipment. IFFM-D Flow Injection Bioluminescence Analyzer, IFFS-A Multifunctional Chemiluminescence Detector; SYZ-B Type Quartz Boiler High Pour Water Distiller; 515 High Performance Liquid Chromatograph, 2487 High Sensitivity Dual Channel UV Detector; U (2005mm electronic balance; 3k15 centrifuge; vortex mixer); electric heating constant 
temperature blast oven; FA2004A electronic balance; 3k15 centrifuge;

Method. Preparation of solution. $1.0 \times 10-2 \mathrm{~mol} / \mathrm{L}$ Acrylamide standard solution: accurately weighed $55{ }^{\circ} \mathrm{C}$ baking to constant quality of acrylamide $0.0355 \mathrm{~g}$ in a small beaker, with $0.1 \mathrm{~mol} /$ LED TA-2N a solution dissolved and set at $50 \mathrm{~m}$ L capacity bottle.

$2.0 \times 10-2 \mathrm{~mol} / \mathrm{L}$ Luminol stock solution: accurately called Luminol 3.5432g with 0.10mol / L potassium hydroxide dissolved and set in a 1L brown volumetric flask, mix, keep the light preservation 14d Back-up.

$4.0 \times 10-4 \mathrm{~mol} / \mathrm{L}$ Luminol Analytical solution: Pipet with a pipette $4.00 \mathrm{~m}$ L Luminol stock solution in a $200 \mathrm{~m}$ L volumetric flask, adjusted to $\mathrm{pH}$ to the scale, can be mixed [4].

PH 2.50 aqueous solution: take the quartz sub-boiling re-distilled water $1 \mathrm{~L}$ in the reagent bottle, with hydrochloric acid in the ion analyzer to adjust the $\mathrm{pH}$ value of 2.50 after the reserve.

0.10mol / L EDTA-2N a solution: accurately weighed ethylenediamine tetraacetic acid disodium 9.3050g, with pH2.50 aqueous solution and fixed in the $250 \mathrm{~m}$ L volumetric flask, mix well.

Carrez Reagent I: Weigh $15 \mathrm{~g}$ potassium ferrocyanide dissolved in $100 \mathrm{~m} \mathrm{~L}$ re-distilled water; Carrez Reagent II: Weigh 30g zinc sulfate dissolved in 100m L re-distilled water.

0.50mol / L hydrogen peroxide solution: remove 30g / 100m L hydrogen peroxide solution $10.20 \mathrm{~m} \mathrm{~L}$, with re-steaming capacity in a $200 \mathrm{~m}$ L brown volumetric flask, mix well, the reagent is now available.

The reagents used were analytically pure, and the water was secondary deionized quartz.

The glassware used in the experiment was soaked in a nitric acid solution with a volume fraction of $20 \%$ for 6 hours or more and washed with distilled water.

Sample handling and determination. (About $0.0001 \mathrm{~g}$ ) in $50 \mathrm{~m} \mathrm{~L}$ centrifuge tube, add $10.00 \mathrm{~m} \mathrm{~L}$ re-distilled water, respectively, adding Carrez reagent I, II each $1.00 \mathrm{~m} \mathrm{~L}$, Then add $10 \mathrm{~m} \mathrm{~L} \mathrm{of}$ $\mathrm{n}$-hexane, shake on the vortex mixer $2 \mathrm{~m}$ in, and then placed in a centrifuge on the $10000 \mathrm{r} / \mathrm{min}$ centrifuge $15 \mathrm{~m}$ in, remove the n-hexane removed, the water phase $0.22 \mathrm{~m}$ filter after filtration, Take $2.00 \mathrm{~m}$ L filtrate in $25 \mathrm{~m} \mathrm{~L}$ volumetric flask, with $0.10 \mathrm{~mol} / \mathrm{L}$ EDTA $-2 \mathrm{~N}$ a solution to the volume [5]. The sample was measured under the same conditions as the standard solution. The concentration c / (mol / L) of the acrylamide was determined from the standard curve. The mass fraction of acrylamide in the sample was calculated and the blank was measured.

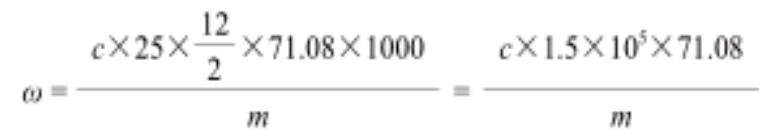

Where: $\omega$ is the mass fraction of acrylamide in the sample / $(\mu \mathrm{g} / \mathrm{g}) ; \mathrm{m}$ is the mass of the sample given / g; 71.08 is the molar mass of acrylamide / ( $\mathrm{g} / \mathrm{ol})$.

\section{The Results and Analysis}

Determination of Ph Value of Luminol Solution. Luminol solution is stronger and more stable under alkaline conditions. Therefore, when the concentration of luminal solution is $6.0 \times 10-4 \mathrm{~mol} /$ $\mathrm{L}$, the concentration of hydrogen peroxide is $0.20 \mathrm{~mol} / \mathrm{L}$, the AM concentration is $1.0 \times 10-8 \mathrm{~mol} /$ L, with $2 \mathrm{~mol} / \mathrm{L} \mathrm{KO} \mathrm{H}$ solution to adjust the luminol solution $\mathrm{pH} 8.00 \sim 13.50$, measured every $0.50 \mathrm{pH} 1$ times to study the acidity of the relative chemiluminescence intensity of the impact.

It can be seen that the $\mathrm{pH}$ of the solution is 0.150 when the relative luminous intensity of the largest, so the choice of $\mathrm{pH}$ value of $12.50 \mathrm{KO} \mathrm{H}$ solution for the reaction medium [6].

Selection of Luminol Solution Concentration. Under the conditions of hydrogen peroxide concentration of $0.20 \mathrm{~mol} / \mathrm{L}$, AM concentration of $1.0 \times 10-8 \mathrm{~mol} / \mathrm{L}$ and luminal solution pH12.50, $1.0 \times 10-5,3.0 \times 10-5$ and $5.0 \times 10-5,7.0 \times 10-5,1.0 \times 10-4,3.0 \times 10-4,4.0 \times 10-4$, 
$5.0 \times 10-4,7.0 \times 10-4,1.0 \times 10-3 \mathrm{~mol} / \mathrm{L}$ The effect of Luminol solution on the relative chemiluminescence intensity was the highest when the concentration of Luminol was $4.0 \times 10-4$ $\mathrm{mol} / \mathrm{L}$. Therefore, the concentration of luminal solution was chosen to be $4.0 \times 10-4 \mathrm{~mol} / \mathrm{L}$.

Linear Range. Use the standard solution of acrylamide series in Section 1.3.1 to determine the operating parameters set in Table 1 under optimized experimental conditions. The standard curve was drawn with the concentration of acrylamide as the abscissa and the relative chemiluminescence value as the ordinate. From the standard curve, it was found that acrylamide had a good linearity in the range of $1.0 \times 10-6$ to $1.0 \times 10-3 \mathrm{~mol} / \mathrm{L}$, the linear equation was $\mathrm{y}=3 \times 106 \mathrm{x}+265.89$ and $\mathrm{r}$ was 0.9993 . When the acrylamide concentration is less than $10-6 \mathrm{~mol} / \mathrm{L}$ or greater than $10-3 \mathrm{~mol} /$ $\mathrm{L}$, the linear equation is deviated. The standard solution of $1.0 \times 10-6 \mathrm{~mol} / \mathrm{L}$ acrylamide was measured 11 times in the same experimental conditions as the sample to be measured. The detection limit was $3.95 \times 10-8 \mathrm{~mol} / \mathrm{L}$.

Spiked Recovery Rate. Under the optimized experimental conditions, the samples were measured five times in parallel, and the results were measured by averaging. At the same time, respectively, with $1.0 \times 10-4 \mathrm{~mol} / \mathrm{L}$ of acrylamide standard solution 250,375 L spike recovery experiments, each spiked level parallel to determine 3 times, check the undoubted value of the average reported recovery rate.

It can be seen that the shrimp, pot bar sample and No. 1 potato chips were not detected acrylamide, No. 2 potato chips in the presence of a small amount of acrylamide. The recoveries of the method were between $91 \%$ and $107 \%$.

Control Results and Precision. The samples were pretreated and tested using W aters 515 high performance liquid chromatograph. The chromatographic conditions were as follows: the mobile phase was water-methanol $(95: 5, \mathrm{~V} / \mathrm{V})$; flow rate $0.3 \mathrm{~m} \mathrm{~L} / \mathrm{m}$ in; injection volume $10 \mu \mathrm{L}$; retention time $10.492 \mathrm{~m}$ in; detection wavelength $197 \mathrm{~nm}$; column temperature $30{ }^{\circ} \mathrm{C}$.

The content of acrylamide in the samples of No.2 potato chips was determined by high performance liquid chromatography and flow injection chemiluminescence. The Q test was used to test the two groups of data without any doubt [7]. The F test and t test showed that there was no significant difference between the two methods, and the confidence degree was $95 \%$.

It was found that the average standard deviation (RSD) of the acrylamide was $2.53 \mathrm{~g} / \mathrm{g}$ and the RSD of the 9th parallel samples was $1.3 \%$ by flow injection chemiluminescence.

\section{Conclusion}

Based on the enhancing effect of acrylamide on luminol - hydrogen peroxide chemiluminescence system, a chemiluminescence method for the determination of acrylamide in fried food was established. The sample pretreatment is simple and rapid, the cost is low, the method is simple and rapid, the sensitivity is high, the detection limit, precision and recovery rate are ideal, and the results are satisfactory for the determination of acrylamide in fried food.

\section{References}

[1] FANG Dao-bin, GUO Rui-wei, HAN Run-hua, et al. Acrylamide polymer [M]. Beijing: Chemical Industry Press, 2006: 183.

[2] SH ARP D. Acrylam ide in food [J]. Lancet, 2003, 361 (2): 361 - 362

[3] Liu Jiyan, Jiang Guibin. Acrylamide in Food and Its Formation Mechanism[J]. Progress in Chemistry, 2004, 16 (6): 416-418. 
[4] Guo Zhifeng, Zhang Lixia, Wang Jiaqiang, et al. Determination of Acrylamide Content in Grades by G C / M S [J]. Analysis Laboratory, 2009, 28 (12): 91-93.

[5] HOU De, CHEN Cun-xi, CHENG Lei, et al. Determination and analysis of acrylamide content in baked wheat germ [J]. Journal of Beijing Technology and Business University: Natural Science Edition, 2011, 29 (1): 10-14.

[6] Zhou Yu, Zhu Shengtao. Determination of Acrylamide: Acrylamide Contamination Level in Fried and Baked Food by Gas Chromatography [J]. Physical Testing and Chemical Analysis: Chemical Journal, 2007, 43 (11): 928-930.

[7] Duan Jinfeng, Zhang Xulong, Shi Ruifen, et al. Determination of acrylamide in instant noodles by high performance liquid chromatography [J]. Chinese Journal of Analytical Chemistry, 2010, 29 (11): 41-44.

李蕴（1982-1）, 女, 吉林长春人, 汉族, 学历: 吉林农业大学应用化学专业硕士研究生, 职称: 实验师。研究方向: 应用化学。

张秀丽 (1983-8), 女, 吉林长春人, 汉族, 学历: 东北师范大学物理化学专业硕士研究生, 职称: 讲师, 研究方向: 化学

邮寄地址: 吉林省长春市经开区锦绣东方45栋1002室, 李蕴收

邮箱: 275632243@qq.com

电话: 13844045594 